Article

\title{
Commonly used external TAM variables in virtual reality, e-learning and agriculture applications: $A$ literature review using QFD as organizing framework
}

\author{
Ivonne Angelica Castiblanco Jimenez*D, Laura Cepeda García, Maria Grazia Violante, and \\ Enrico Vezzetti \\ Department of Management and Production Engineering, Politecnico di Torino, Corso Duca degli Abruzzi 24, \\ 10129 Torino, Italy; laura.cepeda@studenti.polito.it (L.C.G.); mariagrazia.violante@polito.it (M.G.V.); \\ enrico.vezzetti@polito.it (E.V.) \\ * Correspondence: ivonne.castiblanco@polito.
}

\begin{abstract}
In recent years information and communication technologies (ICT) play a significant role in all aspects of modern society and impact socioeconomic development in sectors as education, administration, business, medical care and agriculture. The benefits of such technologies in agriculture can be appreciated only if farmers use them. In order to predict and evaluate the adoption of these new technological tools, the technology acceptance model (TAM) can be a valid aid. The paper measures the potential acceptance of an e-learning tool designed for EU farmers and agricultural entrepreneurs. Starting from a literature review of the technology acceptance model, by analyzing the most commonly used external variables in the fields of e-learning, Agriculture, and Virtual reality, the analysis shows that computer self-efficacy, individual innovativeness, computer anxiety, perceived enjoyment, social norm, content and system quality, experience and facilitating conditions are the most common determinants addressing technology acceptance. Furthermore, findings evidenced that the external variables have a different impact on the two main beliefs of the TAM Model, Perceived Usefulness (PU) and Perceived Ease of Use (PEOU). This study is expected to bring theoretical support for academics when determining the variables to be included in TAM extensions.
\end{abstract}

Keywords: TAM, e-learning, agriculture, virtual reality, QFD, technology acceptance.

\section{Introduction}

In the current high-speed connected world, there is a growing awareness of the advantages offered by information and communication technologies (ICT) and their crucial role in fostering human progress, promoting knowledge societies, supporting sustainable development [1] and accelerating economic growth [2]. Hence, integrating ICTs in all aspects of socio-economic agendas has become a cutting edge challenge [3], and, as years go by, billions of dollars are invested in technological initiatives in various development sectors [4]. However, the benefits of such technologies can only be appreciated if people use them [5].

Researchers from different science and technical areas have developed a set of complementary and extended frameworks to predict and evaluate the adoption of new technological tools. The most diffused approach is the Technology Acceptance Model (TAM), proposed by Davis [6]. This model investigates the drivers of technology acceptance, from the perspective of users' perceptions about innovations and social and contextual factors. The validity of the TAM has been examined in sectors such as food industry [7], wearable technologies [8], health [9], social media [10], electronic commerce [11], energy services [12], financial services [13], among others. Under this model's theoretical and practical logic, we want to measure the potential acceptance of an e-learning tool designed for $29 \mathrm{EU}$ farmers and agricultural entrepreneurs within an European Erasmus + project (FARMER 4.0-Farmer teaching and training laboratories). 
Farmer4.0 wants to actively contribute to the achievement of the objectives of the EU priority "developing a new training model to stimulate a transfer of skills between "traditional" farmers, technologists, researchers and agricultural entrepreneurs of the digital age. EU agriculture suffers from delays in keeping up with modern technologies and skills, which would allow a greater safeguard of the competitive advantage with respect to the aggression of non-EU markets. Thanks to the proposed training, the agricultural entrepreneur of the digital age (farmer4.0) could be able to use the most modern digital manufacturing technologies to create tools, models and practices that will revolutionize the agricultural sector.

From a more general perspective, in this paper we intend to identify the external determinants of acceptance of a 3D virtual learning environment designed in the Farmer4.0 project, where farmers can use new technologies of digital creativity due to the presence of high-quality solutions interactivity. We want to understand how traditional farmers, people who are used to getting by and who find solutions when problems arise using hands and traditional tools, are ready for new digital technologies.

In order to structure the literature review on TAM in a way that is easier to comprehend the relationships between research topics and TAM variables, Quality Function Deployment (QFD) methodology was used. In general the QFD offers the possibility to systematically identify fundamental aspects in the analysis and depict the variables of interest in the same layout, rank them, and examine the existing relationships. On this basis, we considered the QFD to be the most appropriate framework to give a solid foundation to our study, assuring a user-centered perspective.

The present study pursues a threefold objective: 1) Identify and prioritize the most commonly used external factors affecting the two primary constructs, such as perceived usefulness (PU) and perceived ease of use (PEOU) of the Technology Acceptance Model (TAM) in e-learning, agricultural and virtual reality innovations. Those three sectors are selected based on the innovative tool's nature under analysis. 2) Identify the main research topics addressed in the literature of TAM in e-learning, agriculture and virtual reality. 3) Extend the application of the Quality Function Deployment (QFD) as an organizing framework for the literature review. The results obtained are useful for academics and practitioners conducting similar research to have a general idea and theoretical evidence about the external factors driving the acceptance of technologies. The paper starts with a brief description of the TAM and QFD models (section 2) and the proposed research methodology (section 3). Then, we proceeded to the case study (section 4) and discussion (section 5), to analyze thanks to QFD the most commonly used external variables in the fields of e-learning, agriculture, and virtual reality that affected perceived usefulness (PU) and perceived ease of use (PEOU) of the Technology Acceptance Model. Finally, we reported our conclusions and future directions of investigation in section 6 .

\section{Background research models}

\subsection{The Technology Acceptance Model}

In 1985 Fred Davis developed The Technology Acceptance Model (TAM) [6] as a contribution to the field of Management Information Systems (MIS). Since its origin, the model has been a significant step forward in the research area because it enhances the design and development of information systems and represents a practical testing tool to assess systems acceptance in ex-ante use scenarios. Its applicability and validity in a wide range of contexts make it the most utilized theoretical model in Information Systems (IS) [14,15]. Figure 1 depicts the model.

To uncover the reasons behind computer-based technology adoption, Davis adapted the Theory of Reasoned Act (TRA) [16] and the Theory of Planned Behavior [17] to the technology context. Generally speaking, those two complementary theories formulate that there is a sequence of causal relationships among what individuals believe about using a system and the actual use. The authors state that users' beliefs influence the attitude, which in turn modifies the intention to use or not a given technology. The intention is the primary determinant of actual use. On this basis, Davis [6] identified two main beliefs, namely Perceived Usefulness (PU) and Perceived Ease of Use (PEOU), which are defined as [18]: 
$\mathrm{PU}$ is "The degree to which the person believes that using the particular system would enhance her/his job performance."

On the other hand,

PEOU is "The degree to which the person believes that using the particular system would be free of effort."

According to the TAM, the two main determinants, PU and PEOU, are affected by external and context-dependent factors. In this sense, the TAM's consolidation has been a multi-stage process [19], and multiple extensions have been developed according to the research field. TAM 2 and TAM 3 are the prevailing and more comprehensive extensions. The TAM 2 by Venkatesh and Davis [20] focuses on the factors influencing PU and some mediating variables, while TAM 3 unveils the aspects accountable for PEOU [21]. King and He [22] elucidated that there were different types of TAM's applications and classified them in four groups [23] based on whether the analysis focus was: a) factors predicting PU and PEOU, b) factors included from other technology acceptance frameworks, c) variables with potential moderating or controlling effect, and d) consequent factors which are the attitudes and usage. The present study belongs to the first type as it aims to identify commonly used variables influencing PU and PEOU in three specific sectors: e-learning, agriculture and virtual reality.

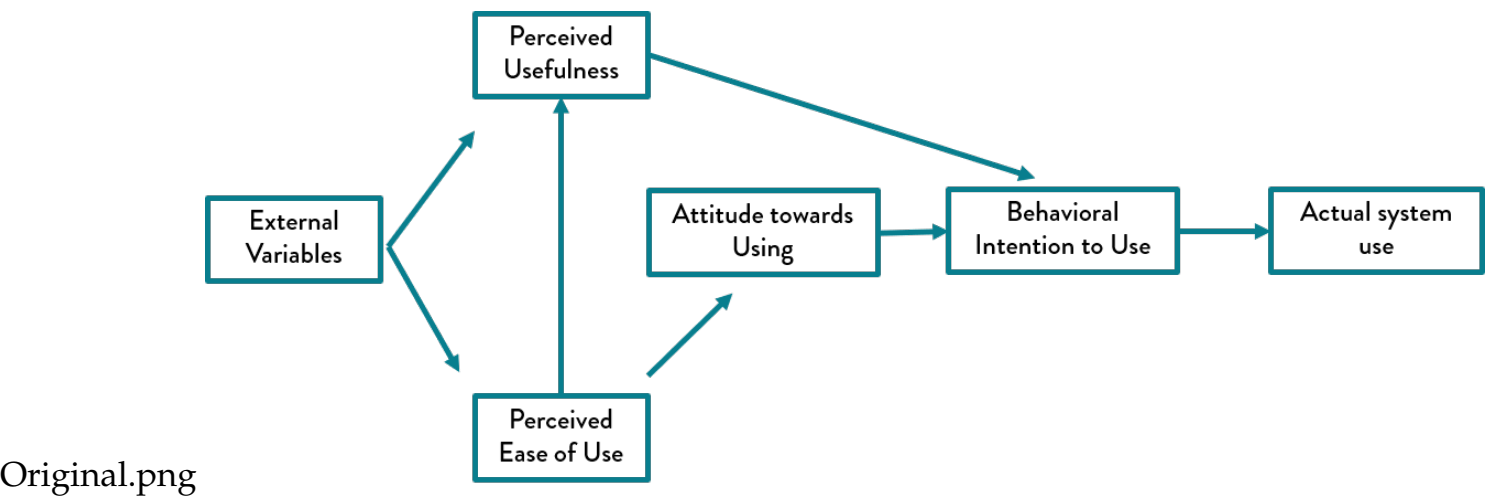

Figure 1. Original Technology Acceptance Model (TAM) Davis et al.

\subsection{The Quality Function Deployment}

The Quality function deployment (QFD) is a practical customer-driven tool particularly appreciated for product design and development [25-27]. This framework was introduced in 1960 by Yoji Akao and appropriated by Mitsubishi in 1972 [28-30]. The general purpose of the QFD is to act as a bridge between what customers want (Customer Requirements (CRs)) and the manners in which products or services will respond with their design features (Technical Characteristics (TCs)) to those desires. Therefore, the QFD provides a systematic structure to map user needs and identify and prioritize design parameters to address those needs from an organizational perspective: there will be the assessment of the impact of design characteristics on customer needs, as well as the correlations among design features and the corresponding prioritization. [25,31-34].

Many authors have implemented the QFD in their studies addressing the design of products and services with particular focus on customer experience and alternative ways to capture user's feedback as in the works by Iranmanesh et al., Choi et al., Vezzetti et al., Violante et al., Sun et al. [35-39]. The reputation of the QFD as a reference framework for design and quality management can be attributable to the multiple advantages it offers. Dolgun and Köksal [34] investigated the main benefits of the framework reported in the literature and among the most outstanding they found: i) improves customer satisfaction by granting users involvement during the design process, ii) allows a more informed and documented decision-making regarding customer demands and the company possibilities to satisfy them, iii) strengthens team communication, iv) reduces time to market and costs by minimizing the risk of errors. 


\section{Method}

For the analysis of the literature the study was based on QFD and structured in 3 phases (figure 2): definition of research categories in TAM, identification of commonly used TAM variables, and analysis of the strength of the relationships represented by the path coefficients.

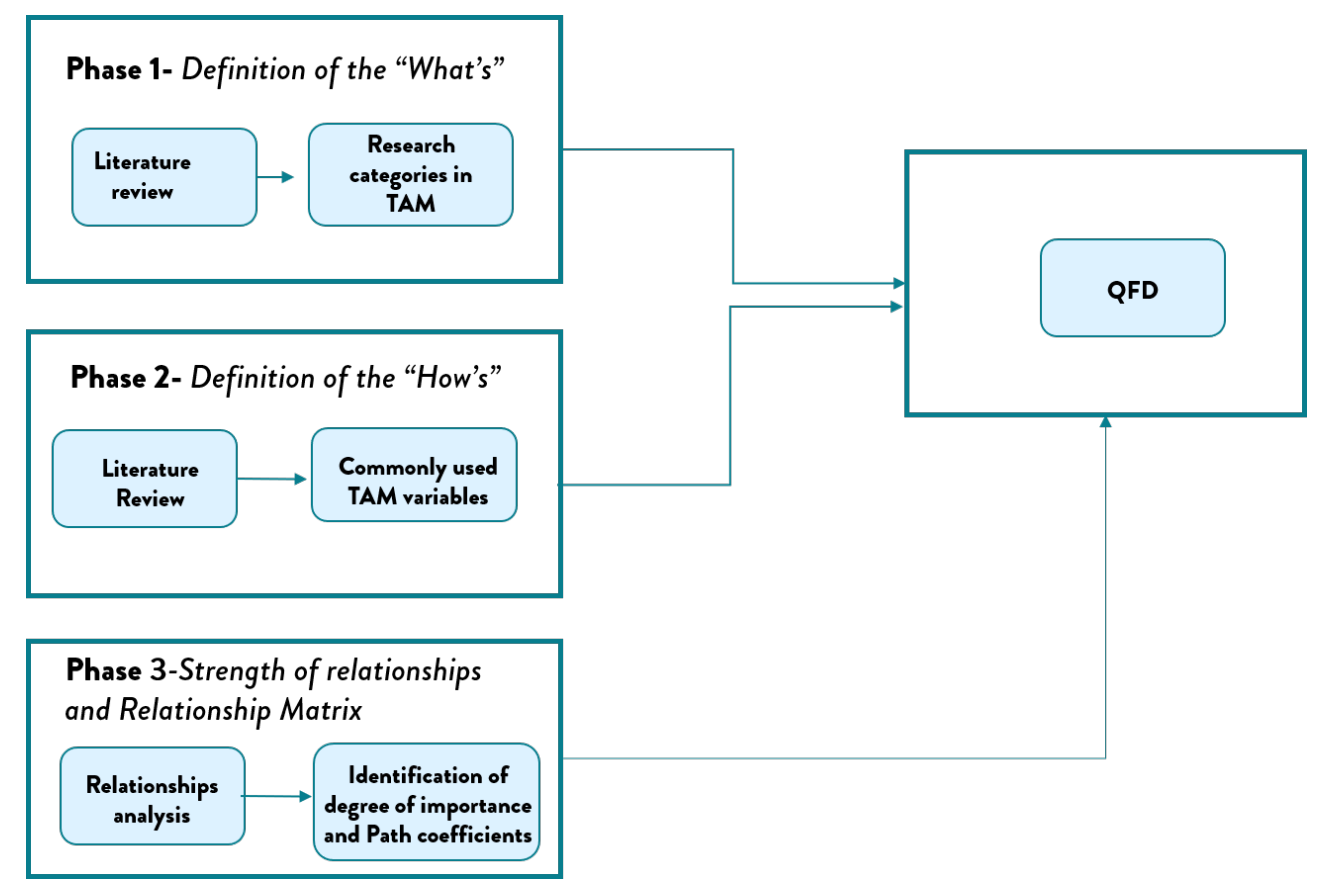

Figure 2. Layout of the proposed methodology.

The aim of the initial phase was to group the research topics in research categories in TAM, equivalent to the customer requirements (CRs) or What's of the HoQ matrix. The second phase corresponds to the identification of the most frequently used external variables in TAM extensions that in the context of our research can be understood as the technical requirements (TCs) or How's of the traditional QFD approach.

For these purposes we conducted a literature review of theoretical and empirical studies within the last ten years and grouped them into seven categories according to the topic and the research perspective. Papers were selected similarly to the quantitative meta-analysis proposed by Abdullah and Ward [5] and adapted for this study, to identify commonly used external factors in TAM extensions in e-learning, agriculture and VR. In the third phase a more strict selection of papers was done in order to analyze the degree of importance of the research categories (What's) and the strength of the relationships between commonly used TAM variables (How's) and the two main constructs of TAM, PU and PEOU. The degree of importance is represented by the number of works belonging to each research category. The strength of the relationships between most common external variables and PU and PEOU is represented by the path coefficient. Therefore, only studies reporting the path coefficients were considered. Finally, we gathered the previous information to construct the QFD matrix proposed in figure 3. The papers' selection and classification process is explained in detail in figure 4 . 


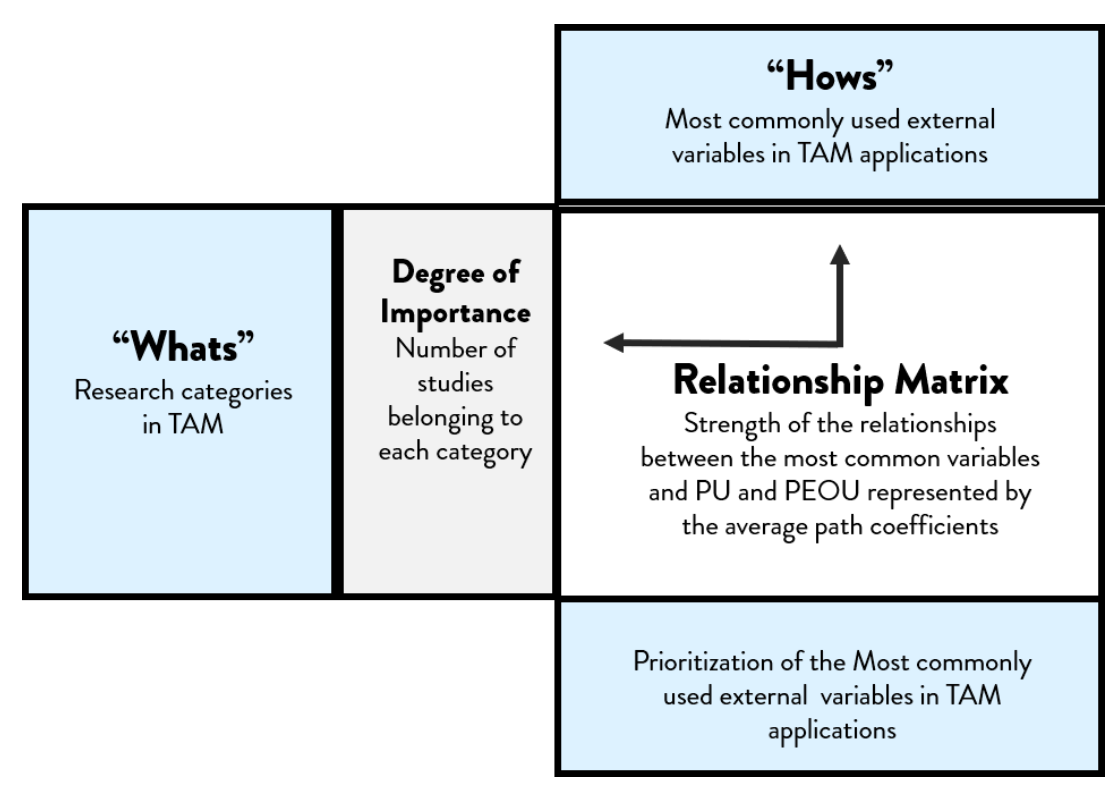

Figure 3. Proposed QFD matrix.

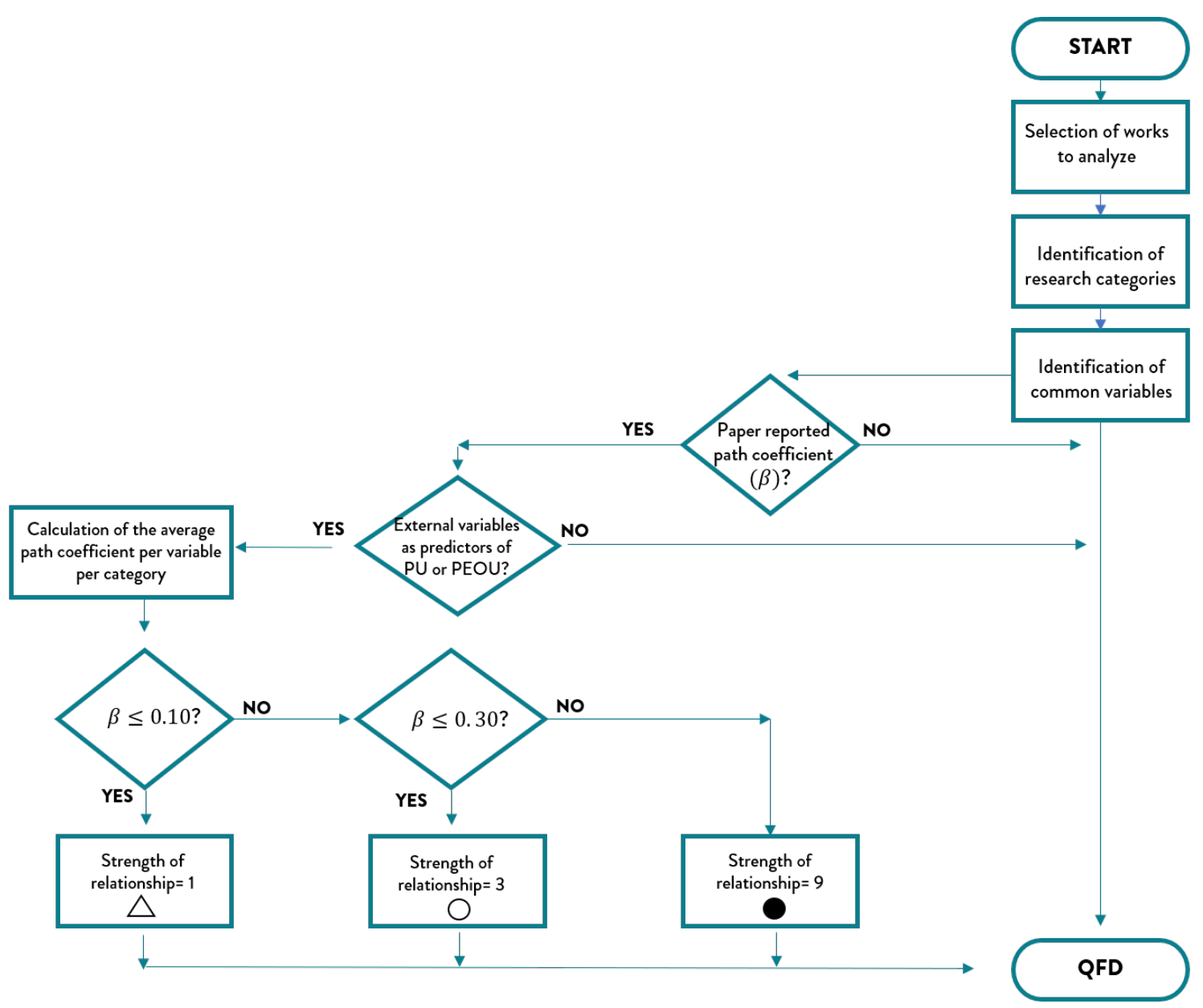

Figure 4. Papers selection process

\section{Case study}

To analyze the current state of the art of the technology acceptance model and apply QFD, we followed the selection criteria mentioned in the methodology and obtained a first sample of 67 papers. 
The selected works were further analyzed to identify types of applications and the recurrent variables used in TAM extensions.

\subsection{Phase 1-Definition of the "What's"}

We started by analyzing the researchers' perspectives on the main objectives for the implementation of the TAM. In our study's QFD application, the customer requirements are represented by the different topics that our potential customers, i.e., the researchers, want to approach by using the TAM. We found that the topics could be divided into seven categories addressing the determinants of the acceptance of innovations as shown in table 1.

Table 1. Identified research categories

\begin{tabular}{cc}
\hline Defined categories & Number of studies \\
\hline Technology acceptance: theoretical models & 7 \\
Acceptance of a bundle of technologies & 6 \\
Acceptance of a methodology & 6 \\
Acceptance of a device & 8 \\
Acceptance of a service/platform/system & 30 \\
Comparison of the acceptance among different tasks or technologies & 3 \\
Technology acceptance: the effect of certain moderating variables & 7 \\
\hline
\end{tabular}

\subsubsection{Technology acceptance: theoretical models}

Works classified under this category include extensive literature reviews whose objective was to propose theoretical models to predict and evaluate the technology acceptance or systematically analyze previous empirical research. Abdullah and Ward [5] developed a General Extended Technology Acceptance Model for e-learning (GETAMEL) by analyzing the external variables used in TAM extensions from the perspective of technology and user types. Similarly, Salloum et al. [40] explored the literature in the field of e-learning to identify the most commonly used external factors explaining students' acceptance. The resulting model was validated with students of five universities in the United Arab of Emirates (UAE). Wingo et al. [41] organized a literature review considering each one of the constructs of the TAM2 and used the results to evaluate faculty's adoption of online teaching practices. In this same context, Scherer et al. [42] conducted a throughout literature review to deepen and synthesize TAM studies in digital technologies in education. The acceptance of everyday technologies in the context of education, such as mobile technologies, have been analyzed using TAM as in work by Sánchez-Prieto et al. [43] who developed a model to evaluate teachers' intention to use mobile technologies in formal education. A more profound analysis of TAM applications in M-learning is presented in the research by Al-Emran et al. [23]. In the Virtual reality field, Tom Dieck and Jung [44] adopted a qualitative approach to identify the external dimensions influencing the acceptance of a mobile augmented reality application. The results were included in an extended TAM, especially useful for virtual reality innovations within the tourism sector.

\subsubsection{Acceptance of a bundle of technologies}

Empirical works grouped under this category measured the acceptance of a set of available technologies and practices analyzed as a whole and without making specific distinctions of any nature. For instance, Silva et al. [45] recognized the complementarity existing among sustainable agricultural practices and studied the adoption and use of Integrated Production technologies by Brazilian common beans' farmers. In an attempt to measure the potential acceptability of smart farm technologies for guava farmers in Thailand, Tubtiang and Pipatpanuvittaya [46] developed and validated an extension of TAM. Analyzing these technologies as a bunch was fundamental to determine the impact of their implementation in the farming supply chain. Far and Rezaei-Moghaddam [47] explored the experts, i.e., personnel and consultants' intention to use precision agricultural technologies (PA). Since PA is 
defined as a combination of information and communication technologies allowing the technical and environmental optimization of resources in agriculture [48], we classified this study belonging to this category. Another bundle of techniques is that consisting of the available tools for food manufacturing. The paramount role of the food processing sector to overcome economic development challenges of the increasingly growing world population aroused the interest of Okumua et al. [49] whose study focuses on the acceptance of food processing technologies by micro and small entrepreneurs in Kenya. A recent work by Rezaei et al. [50] assessed the adoption of Integrated Pest Management (IPM) practices by Iranian tomato growers. In the context of the study, PEST practices include cultural, mechanical, chemical, and biological strategies to reduce and refrain the negative impact of plant pests, improving farm sustainability [51]. As for the e-learning sector, Nam et al. [52] applied the TAM to investigate the ultimate effect of its constructs on the acceptance of assistive technologies by special education teachers. According to the definition provided by Cowan et al. [53], assistive technology covers any device or system that makes possible the execution of a task safely and facilitates the performance, impossible to obtain otherwise.

\subsubsection{Technology acceptance when the technology is a device}

The TAM was initially conceived as a framework to understand the grounds for computer technology acceptance [6]. In keeping with its initial purpose, Teo et al., Teo $[54,55]$ validated the TAM in an attempt to identify the factors predicting pre-service teachers' intention to use computers at the National Institute of Education in Singapore, and Wong et al. [56] studied teachers' intention to use computers in their pedagogical practices in a university in Malaysia. Analogously, Sánchez-Prieto et al. [57] examined the behavioral intention of primary education teacher students of the University of Salamanca, towards to use mobile devices for teaching practices to be developed in the future. Cellular technologies are attractive tools for educational purposes and also have a fundamental role in fostering rural development. With that in mind, Islam and Grönlund [58] surveyed the adoption reasons for mobile phones among farmers in Bangladesh. The proposed Rural Technology Acceptance Model (RUTAM) pointed out the significant influence of social ties at the early stages of adoption. Carrying on with the agricultural sector, Zhou et al. [59] delved into the attributes responsible for a favorable reception of solar water pump (SWP) technology among rural farmers of Pakistan. The outcomes confirm the influence of perceived usefulness and perceived ease of use on SWP usage. On VR technologies, the TAM was tested to determine the acceptance of googles [60] and virtual reality devices in general [61]. In both cases, perceived enjoyment was a significant and positive predictor of attitude towards using and purchasing.

\subsubsection{Technology acceptance when the technology is a service/platform/system}

The number of articles belonging to this category is significantly higher than the others, totaling thirty-one works. The recurrent TAM applications of this nature can be due to the extensive Internet use and its paramount role in developing new technologies [62] thanks to the advantages it offers, such as speed and reliability [63]. This categorization contains TAM applications to predict and evaluate the acceptance of specific software, systems, or platforms. The most customary TAM validation within the e-learning sector is to assess the acceptance of learning management systems (LMS) as in the works by Alharbi and Drew, Shin and Kang, Calisir et al., Mohammadi, Al-Rahmi et al., Binyamin et al., Al-Adwan et al., Fathema et al., Chang et al., Al-Gahtani and Lee et al. [64-74]. Regarding learning environments, contributions on TAM research have been made by Yeou, Estriegana et al. [75,76] and Shyu and Huang [77] and authors like Wu and Chen and Revythi and Tselios [78,79] have investigated the intention to benefit from online courses. Understanding users' motivations that trigger instructional resources acceptance is a key process in developing learning platforms and systems. Amongst the examined tools are Compliant Learning Object (SCLO) [80], educational wikis [81], web feeds [82], platforms supported by google sites and apps [83], as well as apps such YouTube for learning assistance [84]. Moving to the agricultural field, Vidanapathirana et al. [85] tested an Online Agro-technology 
Diploma program from the TAM perspective. Moreover, innovative technologies like mobile-based agricultural services and information systems were under the scope of analysis of the work by Verma and Sinha, Verma and Sinha [86,87] and Mercurio and Hernandez [15]. Some other interesting TAM implementations evaluated farmers' intention to use a microfinance platform [88], the acceptance of a QR Code for a food traceability system [7] and the usage of Cloud Computing technologies for farming in Ireland [89]. As for the VR sector, the contributions made by Huang and Liao and Huang et al. $[90,91]$ explored the determinants of acceptance of augmented-reality interactive systems.

\subsubsection{Comparison of the acceptance among a set of tasks/technologies}

TAM application in this type of study is not very diffused. Only three papers were found to analyze the TAM to understand users' preferences of specific techniques, technologies, or tasks over others. Broadly speaking, these studies evaluated how the TAM constructs, such as perceived usefulness and perceived ease of use, tilted the balance in favor of some innovations. In the agriculture field, Naspetti et al. [92] contrasted three environment-friendly production techniques: Agroforestry, Alternative protein source, and Prolonged maternal feeding, and validated the predictive power of perceived usefulness over the intention to use. Caffaro et al. [93] tried to understand the factors responsible for the scarce adoption of smart farming technologies (SFTs). The authors clustered some SFTs into two groups: drones, sensors for data acquisition and automatic download, and agricultural apps belonged to the first type. Agricultural robots and autonomous machines formed the second one. They also investigated the effect of exposure to different forms of interpersonal communication on perceived usefulness and perceived ease of use. As for the e-learning sector, Schoonenboom [94] examined teachers' intention to use a learning management system for eighteen instructional tasks. The results showed that using the LMS is preferred for some activities, mainly due to task importance, LMS' usefulness for performing the job, and the ease of use.

\subsubsection{Acceptance of a methodology}

We found theoretical evidence that the TAM has been validated not only at product/service level but also it has the potential to predict the acceptance at process/practice level. Specifically, this category gathers papers analyzing the implementation of a particular methodology by looking beyond the mere technologies involved. Sharifzadeh et al. [95] examined the acceptance of a behavioral control strategy, namely, the use of Trichogramma spp for pests control by Iranian rice farmers, broadening the existent research body on crop protection techniques. Bahtera et al. [96] validated the TAM to provide a strategic perspective for the use of the internet in agricultural endeavors that is frequently overlooked. The authors emphasized the outstanding importance of marketing strategies for farmers' welfare and tried to understand the determinants of ICT use for this specific purpose. In the learning sector, e-learning and mobile learning, as well as mobile-based assessment, were analyzed from a methodology perspective. Several investigations look at students' acceptance of e-learning as a novel learning method. Punnoose [97] dug into the determinants of student's intention to study remotely by polling a sample of master scholars from the Assumption University of Thailand. This concern was also discussed in the research by Ibrahim et al. [98] validated with 95 undergraduate students at Tunku Abdul Rahman University College (TARUC). As for mobile learning, significantly fewer studies have addressed this methodology and analyzed its advantages and shortcomings over e-learning. Park et al. [99] investigated the process by which Konkuk university students adopted mobile learning and focused on the possibilities for learning evaluation through handheld or palmtop devices. Nikou and Economides [100] validated the TAM in the context of mobile-based assessment.

\subsubsection{Technology acceptance analyzing the effect of certain moderating variables}

In addition to the original TAM determinants, PU and PEOU, papers under this category give special attention to the moderating role of some variables being age and gender the most used. Ahmad et al. [101] applied an extension of the TAM in a public university in Malaysia to understand how age 
and gender affected the acceptance of computer-based technologies by faculty members. The results evidenced that the causal relationships among exogenous variables and the TAM were invariant for female and male staff members. However, age seemed to have moderating effects over the use of technology. In line with the previous study, Wong et al. [102] analyzed the influence of gender in student teachers' intention to use computers. Once more, the findings showed that gender had no moderating effects within the context of the study. Unlike the precedent researches, Padilla-Meléndez et al. [103] found that females had a higher perception of playfulness and attitude towards the use of blended learning environments than males, and males, on the other hand, seemed to have higher intention to use this type of technology. Tarhini et al. [104] explored the moderating effect of age and gender in the students' acceptance of a Web-based learning system at Brunel University in England. The study outcomes reflected that younger students had a higher perception of usefulness, while older users perceived the system more comfortable to use. Gender was also found to affect some of the relationships within the extended TAM. In addition to gender influence on TAM factors, Al-Azawei and Lundqvist [105] considered the effect of students' learning styles defined by Felder et al. [106], namely, active, sensing, visual and sequential learners, on user satisfaction towards an online learning system. No gender nor learning styles reported significant effects. Likewise, Al-Azawei et al. [107] assessed the impact of learning preferences in a blended e-learning system (BELS). They found no mediating relationships among those psychological traits and learner satisfaction or e-learning adoption. From a cultural approach, Tarhini et al. [108] investigated the effects of four cultural dimensions of individuals on the adoption of e-learning tools by students in Lebanon. The research included the factors masculinity/femininity, individualism/collectivism, power distance, and uncertainty avoidance within the TAM. The validation process evidenced the existing relationship between culture and social norm, perceived usefulness, and perceived ease of use.

\subsection{Phase 2-Definition of the "How's"}

The aim of this phase was to identify the external variables that academics and practitioners included more frequently in TAM extensions, in order to approach the research purposes. After individuating the variables included by each one of the selected studies, we calculated the frequency of appearance of each one of the determinants. The most common variables are depicted in table 2 . The definitions of each one of the identified variables are provided in table 3.

Table 2. Most commonly used external variables in TAM applications.

\begin{tabular}{cc}
\hline External variables & Included in the proposed model of studies \\
\hline Anxiety & 7 \\
Content quality & 11 \\
Experience & 7 \\
Facilitating conditions & 10 \\
Individual innovativeness & 8 \\
Perceived enjoyment & 8 \\
Self-efficacy & 30 \\
Service/System quality & 7 \\
Social norm & 24 \\
\hline
\end{tabular}


Table 3. Definitions of the "How's"

\begin{tabular}{|c|c|}
\hline External variable & Definition \\
\hline Anxiety (ANX) & $\begin{array}{l}\text { "An individual's apprehension, or even fear when she/he is faced with } \\
\text { the possibility of using computers." }[21,109] \text {. }\end{array}$ \\
\hline Content quality (CQ) & $\begin{array}{l}\text { Extent to which the information fits user needs [110] in terms of } \\
\text { information organization, relevance and actuality [111], availability of } \\
\text { support materials, and accuracy of the terminology [69]. }\end{array}$ \\
\hline Experience (EXP) & $\begin{array}{l}\text { Past interactions or exposure of an individual to a system and the } \\
\text { accumulated knowledge gained by usage [112-114]. }\end{array}$ \\
\hline Facilitating conditions (FC) & $\begin{array}{l}\text { Users' beliefs about the existence of technical and organizational } \\
\text { resources and infrastructure to facilitate the use of technology [115]. }\end{array}$ \\
\hline Individual innovativeness (II) & $\begin{array}{l}\text { Individual's disposition towards adopting any new technology before } \\
\text { others }[116,117] \text {. }\end{array}$ \\
\hline Perceived enjoyment (PE) & $\begin{array}{l}\text { Refers to how pleasant and entertaining is the use of the innovation, } \\
\text { separately from any performance consequence that can be deducted from } \\
\text { system usage }[43,109,118] \text {. }\end{array}$ \\
\hline Self-efficacy (SE) & $\begin{array}{l}\text { User's confidence in his/her capabilities to perform a task, achieve a } \\
\text { specific goal, or produce the desired outcomes by properly using an } \\
\text { innovative system or device [119-121]. }\end{array}$ \\
\hline System quality (SQ) & Technical achievements, the accuracy, and efficiency of the system [122]. \\
\hline Social norm (SN) & $\begin{array}{l}\text { The extent to which the ideas coming from others may foster or } \\
\text { discourage the use of technology }[20,123,124] \text {. }\end{array}$ \\
\hline
\end{tabular}

\subsection{Phase 3-Strength of the relationships and Relationship Matrix}

It is a common interest among academics who develop TAM extensions, to comprehend the relationships existing between external variables and TAM's two main determinants PU an PEOU [5]. For this reason, two QFD matrices, one for each of the TAM's two primary constructs, were constructed and considering that in the TAM, PEOU is also a determinant of PU [6], we included the construct PEOU within the PU matrix to analyze its effect. One of the most commonly reported statistical indexes in TAM studies is the Path coefficient $(\beta)$. Path coefficients indicate not only the strength of the relationships but also the causal effect of the common external factors (independent variables) on the dependent variables (PU and PEOU) and the effect of PEOU on PU as depicted in figure 5 [125].

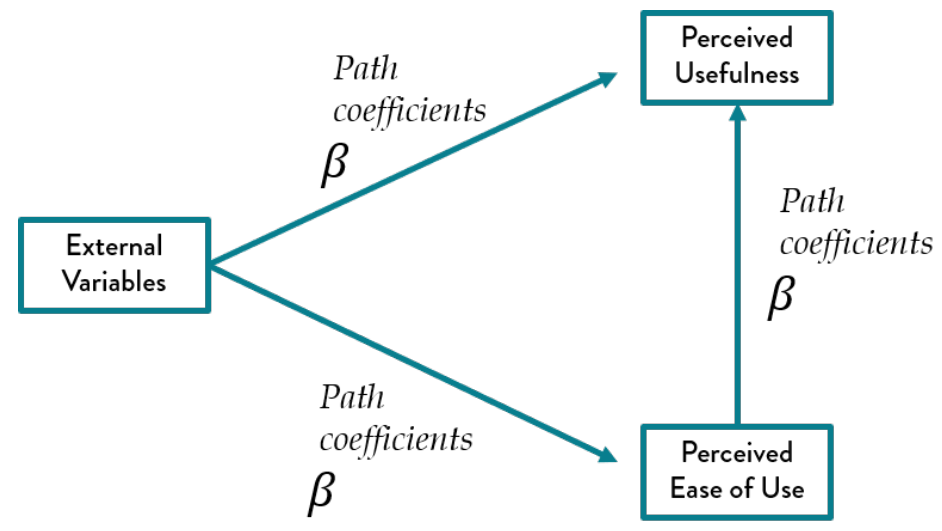

Figure 5. Path Coefficients.

However, some of the analyzed studies did not report this information directly, and in some others, the independent and dependent variables were not directly linked. The number of works grouped in each category reporting the path coefficients is shown in table 4 . In addition, table 4 specifies the quantity of studies reporting the relationship for each one of the TAM determinants, PU and PEOU. 
Table 4. Number of papers reporting path coefficients $(\beta)$

\begin{tabular}{llll}
\hline Research categories & Num. of studies & $\begin{array}{l}\text { Studies with }(\beta) \\
\text { w.r.t. PU }\end{array}$ & $\begin{array}{l}\text { Studies with }(\beta) \\
\text { w.r.t. PEOU }\end{array}$ \\
\hline Technology acceptance: theoretical models & 7 & 3 & 3 \\
Acceptance of a bundle of technologies & 6 & 2 & 2 \\
Acceptance of a methodology & 6 & 3 & 3 \\
Acceptance of a device & 8 & 6 & 6 \\
$\begin{array}{l}\text { Acceptance of a service/platform/system } \\
\text { Comparison of the acceptance among }\end{array}$ & 30 & 16 & 17 \\
$\begin{array}{l}\text { different tasks/technologies } \\
\text { Technology acceptance: the effect of certain }\end{array}$ & 7 & 2 & 0 \\
moderating variables & & 4 & 3 \\
\hline
\end{tabular}

Deviating from the conventional QFD matrix in which the importance of customer requirements is assigned using a Likert scale of points 1 to 5, the degree of importance of our study's research problematics was determined based on the number of studies belonging to each category and reporting path coefficients. The relative importance was calculated as the coefficient of articles per category over the total of works reporting path coefficients.

For the relationship matrix construction, we assigned the values of the relationship between How's and What's using the average path coefficients between external variables and PU, external variables and PEOU and between PEOU and PU. It was followed the criteria suggested by Cohen [126]. Values in the range from 0 to 0.10 included were assigned the value of "1", reflecting a weak relationship. For indexes higher than 0.10 and up to 0.30 included, the importance was "3", indicating a medium relationship. Average coefficients higher than 0.30 were said to have a strong link and importance of "9".

Finally, the technical importance of external variables was calculated by the products' cumulative sum between the degree of importance of each category and the relationships' strength. The relative importance permitted the prioritization of the external variables. The discussion of the findings is present in the following section.

\section{Discussion}

To understand the external variables that could influence the acceptance of a 3D learning environment for farmers in Europe, we consulted previous TAM applications in e-learning, agriculture, and virtual reality sectors. TAM extensions on e-learning technologies have been a research topic for more than a decade [5]. On the contrary, significantly fewer studies investigated the acceptance of VR technologies, and that gap of knowledge is also mentioned in recent work by Sagnier et al. [127]. To facilitate the analysis, we considered the effects of the external variables in PU and PEOU separately. The impact of each factor per category is depicted in figures 6 and 7 . As reported in table 4, only two of the three researches belonging to the category: "Comparison of the acceptance among different tasks or technologies" provided information about path coefficients. However, none of them delved into the determinants of PEOU. On this basis, we excluded the mentioned category from the QFD matrix of PEOU. Considering that in the TAM, PEOU is also a determinant of PU [6], we included the construct PEOU within the PU matrix to analyze its effect. 

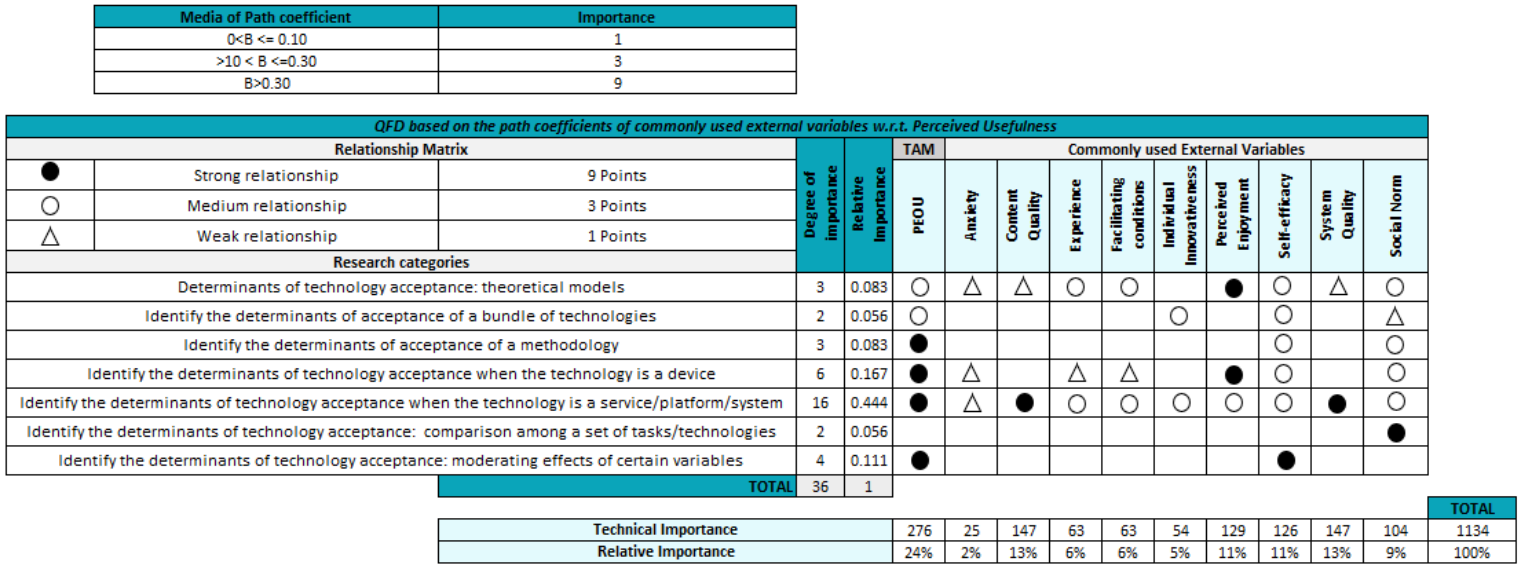

Figure 6. QFD matrix for Perceived Usefulness.

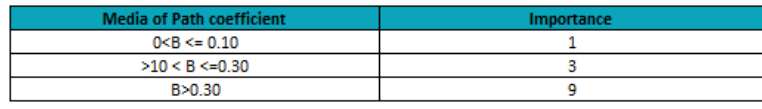

\begin{tabular}{|c|c|c|c|c|c|c|c|c|c|c|c|c|c|}
\hline \multicolumn{14}{|c|}{ ly used extermal variables w.r.t. Perceived Ease of Use } \\
\hline & & & \multirow{5}{*}{ 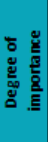 } & \multirow{5}{*}{ 这 } & \multirow{5}{*}{ 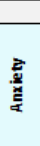 } & \multirow{5}{*}{ 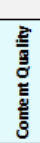 } & Com & nonly us & Sed Ext & ernal Var & ables & \multirow{5}{*}{ 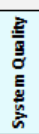 } & \\
\hline (2) & Strong relationship & 9 Points & & & & & \multirow{4}{*}{ 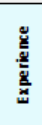 } & \multirow{4}{*}{ 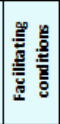 } & \multirow{4}{*}{ 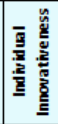 } & \multirow{4}{*}{ 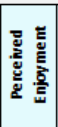 } & \multirow{4}{*}{ 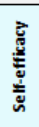 } & & \multirow{4}{*}{$\frac{\mathrm{g}}{\frac{0}{2}}$} \\
\hline 0 & Medium relationship & 3 Points & & & & & & & & & & & \\
\hline$\triangle$ & Weak relationship & 1 Points & & & & & & & & & & & \\
\hline \multicolumn{3}{|c|}{ Research categories } & & & & & & & & & & & \\
\hline \multicolumn{3}{|c|}{ Determinants of technology acceptance: theoretical models } & 3 & 0.088 & 0 & $\Delta$ & 0 & - & & 0 & $\mathbf{0}$ & $\Delta$ & 0 \\
\hline \multicolumn{3}{|c|}{ Identify the determinants of acceptance of a bundle of technologies } & 2 & 0.059 & & & & - & & & O & & \\
\hline \multicolumn{3}{|c|}{ Identify the determinants of acceptance of a methodology } & 3 & 0.088 & & & & & & & O & & $\Delta$ \\
\hline \multicolumn{3}{|c|}{ Identify the determinants of technology acceptance when the technology is a device } & 6 & 0.176 & 0 & & 0 & 0 & & ? & O & & \\
\hline \multicolumn{3}{|c|}{ Identify the determinants of technology acceptance when the technology is a service/platform/system } & 17 & 0.5 & $\mathrm{O}$ & ? & ? & $\mathrm{O}$ & $\Delta$ & - & 0 & O & $\mathrm{O}$ \\
\hline \multicolumn{3}{|c|}{ Identify the determinants of technology acceptance: moderating effects of certain variables } & 3 & 0.088 & & & & & & & ○ & & \\
\hline
\end{tabular}

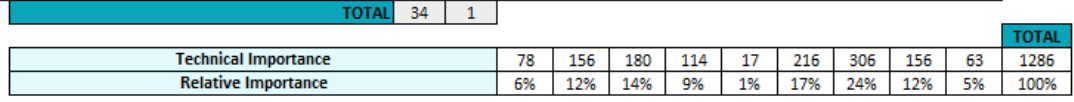

Figure 7. QFD matrix for Perceived Ease of Use.

In general, the findings suggest that the best predictor of PU is PEOU, followed by content and system quality, perceived enjoyment, self-efficacy, social norm, facilitating conditions, experience, individual innovativeness, and finally, anxiety. As for PEOU, it is mainly predicted by self-efficacy, followed by perceived enjoyment, experience, system and content quality, anxiety, social norm, and finally, individual innovativeness. Therefore, we can confirm that the external variables have different effects on PU and PEOU.

PEOU is not an external variable because it is one of the TAM's two main determinants. Studies from the categories measuring the acceptance of a new methodology, a device, and a system or service, reported a strong predictive power of PEOU on PU. That was also the case for studies analyzing the moderating effect of some variables. A weaker but still significant influence of PEOU on PU was found in theoretical models and in cases-study evaluating the acceptance of a bundle of technologies. This study confirmed the presence of a strong and significant impact of the PEOU on PU in most cases, which validates the significance of the relationship established by Davis [6] in the original TAM.

The concept of ANX is often associated with negative feelings of nervousness, fear, and uncertainty about the outcomes of using innovations [57]. Li et al. [128] pointed out that in software applications, the effect of ANX is often analyzed, and that is evident in our study. Only works evaluating the acceptance of a device and a system or service, and theoretical extensions of the model, reported the causal link among ANX and the two main TAM determinants. The average effect size evidenced a weak relationship of anxiety with PU and a medium impact on PEOU. These results are in line with 
the investigation conducted by Van Raaij and Schepers [129], who reported a direct effect of ANX on PEOU and an indirect effect on PU.

$\mathrm{CQ}$ is a variable especially crucial in learning platforms. By designing and organizing the content in a challenging, reasonable, appropriate, and understandable manner, users' autonomy and competence may be enhanced [100]. Solely researchers interested in assessing the acceptance of systems/platforms/or services, which belong to the same category, and theoretical works, registered the direct effect of content quality on PU and PEOU. Theoretical studies reported a weak influence of CQ in PU and PEOU. On the contrary, PU and PEOU of systems, platforms, and services are strongly affected by the CQ. The influence of CQ on PU and PEOU mentioned in the last category is in accordance with the study conducted by Almaiah et al. [130] who reported that CQ has positive effects on the two TAM beliefs.

According to Venkatesh and Bala [21], increasing the EXP will give the user a better idea about the required effort to develop a specific task using the technology [131,132] and may also create a favorable feeling about system usefulness $[74,133]$. In line with those authors, our findings suggest that previous interactions with innovations have a larger effect on PEOU than in PU. Specifically, EXP has a strong predictive influence in PEOU and a medium impact on PU in the systems' acceptance category. In the case of devices' acceptance, prior use has a moderate effect on PEOU and little effect on PU. Literature reviews examined in our study found that EXP has moderate importance in determining PU and PEOU.

FC are a measure of the available resources to support a given behavior [57,59], and the expertise required [19]. Similarly to Cheng et al. [134], we also found evidence that FC can enhance the idea of how easy it can be to perform a task [134]. Our study's outcomes indicate that users' perception of FC is a crucial determinant of PEOU when the acceptance of a set of complementary technologies is being assessed. FC's decisive role in determining the PEOU was also evident in theoretical studies, which in turn reported a medium impact of FC in PU. We also found that when the technology was a system or service, FCs have a medium influence in PU and PEOU. When the research interest was to predict a device's acceptance, FC moderately affected PEOU and slightly determined PU of this type of technology. One of the most noteworthy findings suggests that users PEOU of a bundle of innovations will be strongly influenced by the FC associated with the complementarity of those technologies. Additionally, FC's role is more appreciated when it comes to the use of platforms than in the case of a device.

II is considered a personal trait. An innovative person will be eager to face the risks associated with the early stages of technology readiness and will have more definite intentions to use new IT [135]. We observed that this external factor has a medium-sized relationship with PU in situations in which users have to express their preferences from a group of technologies available. II also moderately influences PU of systems, services, or platforms. For this same category, the importance of II seems to be considerably less in PEOU. Only studies concerning the acceptance of systems reported the relationship between II and PEOU, indicating that its effect is insignificant on PEOU for our research categories.

PE is understood as an intrinsic motivational factor [136]. PE is a significant predictor of PEOU in the context of devices and systems or services acceptance scenarios. The theoretical category reported a medium strength of the relationship between PE and PEOU. PU is also primarily affected by PE of using devices, and this is in line with the category of theoretical studies. As for systems and services, PE has a medium impact on PU.

Compeau and Higgins [120] stated that the higher the SE expectations, the higher likelihood of succeeding in a particular assignment. The effect of SE as an external variable is the most studied in the TAM works we analyzed. Only one category out of seven didn't report the relationship between SE and PU or PEOU, namely, studies comparing a set of technologies. In all the other research topics, SE showed a significantly strong influence on the perception of how ease could be to use technology as Venkatesh and Davis [137] suggested. For PU, the predictive power of SE was strong when moderating 
variables such as gender and age were being contemplated. All the other categories mentioned a medium effect of SE in PU.

As can be expected, the SQ is particularly relevant for studies analyzing the acceptance of a system or service. If a platform does not run smoothly, users may lose interest in using it, and their perception of ease of use will decrease, as well as their satisfaction $[138,139]$. Our study confirmed the results obtained by Almaiah et al. [130], pointing out that SQ has a substantial impact on PU and PEOU of platforms and systems. In contrast, the theoretical studies category reported a minimum effect of SQ on both TAM's determinants.

The logic behind SN is that human behavior is somehow affected by the opinions of the individuals' closer social spheres. In some cases, people may use a technology based on others' perceptions about the convenience of the use over his or her own emotions and beliefs [18]. Our results suggest that social pressure can have a more significant influence on users' perceptions of usefulness than in PEOU. Academic works comparing the acceptance of a set of technologies reported that users tend to perceive innovations as more useful, based on the recommendations of individuals closest to them. In those cases, SN seems to have a strong predictive power on PU. Theoretical studies and researches investigating the acceptance of methodologies, devices, or systems, showed a medium explanatory impact of SN in PU. When innovations are considered a bunch of technologies, $\mathrm{SN}$ had a low effect on PU. Concerning PEOU, theoretical studies registered a moderate effect of $\mathrm{SN}$ on this TAM determinant, as well as studies assessing the acceptance of systems. When the acceptance of a methodology is under analysis, SN seems to have little effect on PEOU.

The main findings and correlations are summarized in figure 8. Only variables reporting a more significant influence in the two TAM's beliefs are included for each of the seven study categories. Common factors used in TAM extensions in the fields of interest are also listed.

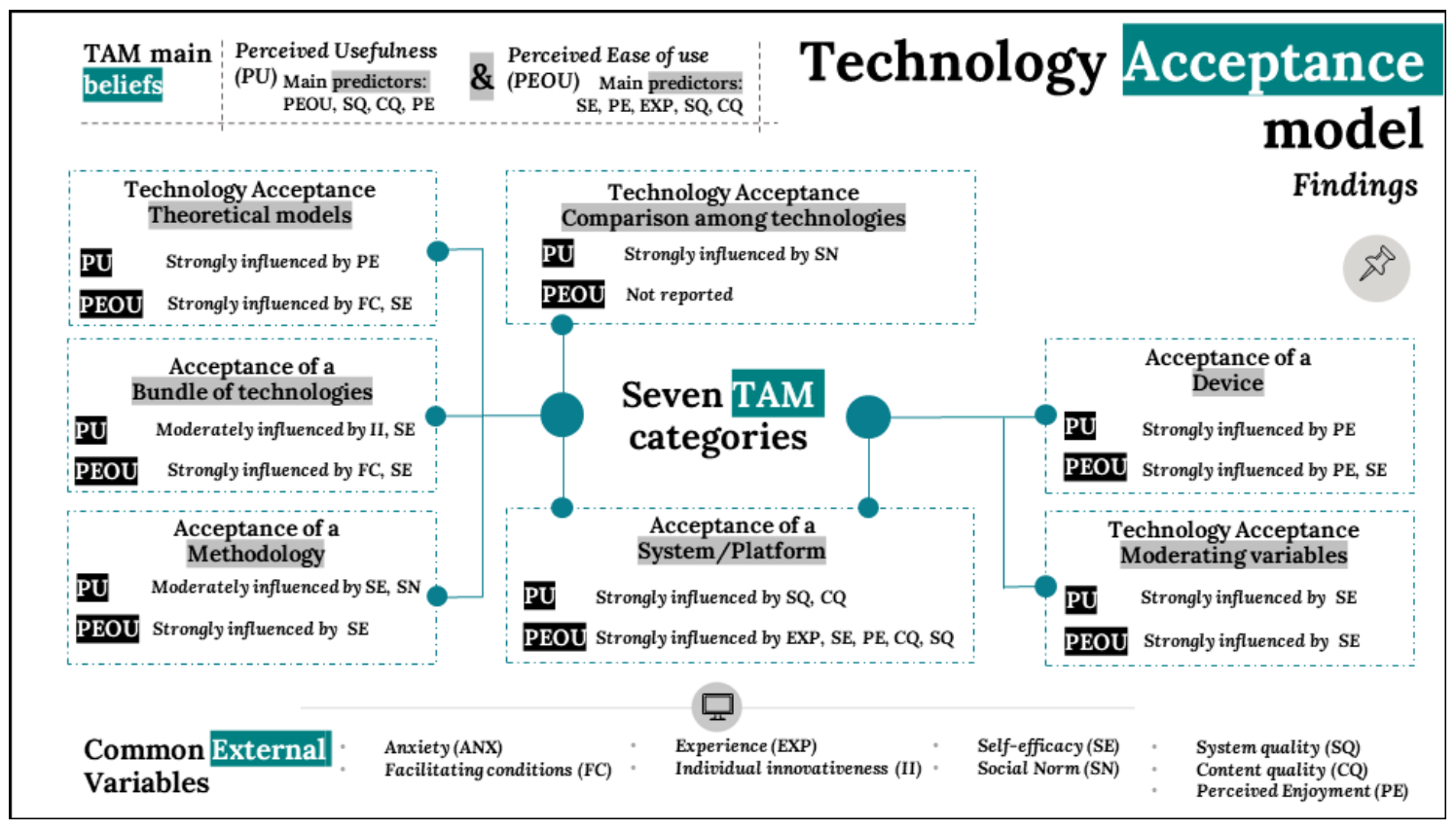

Figure 8. Summary of findings.

\section{Conclusions}

The present study is developed in the context of an agricultural project in Europe. Our objective was to conduct a literature review to identify the most common external variables used in TAM applications using the QFD to give structure to the research. Our analysis focused on three sectors, namely, e-learning, agriculture, and virtual reality. We found evidence that among those three sectors, the less explored is the VR sector. 
By setting apart the variables included in the models we analyzed, we identified the most commonly used variables: anxiety, content quality, experience, facilitating conditions, individual innovativeness, perceived enjoyment, self-efficacy, system quality, and social norm. Our findings provide evidence that external variables influence in a different manner the two personal beliefs proposed by Davis [6] in the TAM. In our case study, PU's primary determinant was PEOU, followed by system and content quality and perceived enjoyment. As for PEOU, it was significantly predicted by self-efficacy, followed by perceived enjoyment, and experience.

The seven research categories and the different impacts of external variables demonstrated the context-dependency of technology use. As an acceptance measurement tool, the TAM provides flexibility and accuracy by leaving the doors open for several extensions and applications.

The QFD proposed in the present study seems to provide a functional framework for organizing and prioritizing the information.

Considering the knowledge gap of technology acceptance in VR innovations and task-level TAM applications, more investigations of those types should be developed. We encourage TAM researchers to provide the existence and validity of relationships along with the effect size. By knowing the variables with a more significant influence on technology acceptance, innovators' efforts will be better oriented.

Author Contributions: Conceptualization, L.C.G., I.C. and M.G.V.; data curation, L.C.G. and I.C.; formal analysis, L.C.G., I.C., and M.G.V.; funding acquisition, M.G.V.; investigation, L.C.G and I.C.; methodology, M.G.V., I.C., and L.C.G.; supervision, M.G.V., I.C., and E.V.; visualization, M.G.V., I.C. and L.C.G.; writing-original draft, L.C.G. and I.C.; writing - review and editing, L.C.G., I.C., and M.G.V.

Funding: This work was supported by European Erasmus+ project "Farmer 4.0", project number: 2018-1-IT01-KA202-006775.

Conflicts of Interest: The authors declare no conflict of interest. The funders had no role in the design of the study; in the collection, analyses, or interpretation of data; in the writing of the manuscript, or in the decision to publish the results.

\section{Abbreviations}

The following abbreviations are used in this manuscript:

TAM Technology Acceptance Model

ICT Information and Communication Technologies

E-learning Electronic Learning

VR Virtual Reality

QFD Quality Function Deployment

HoQ House of Quality

CR Customer Requirements

TC Technical Characteristics

PU Perceived Usefulness

PEOU Perceived Ease of Use

ANX Anxiety

CQ Content Quality

SQ System Quality

EXP Experience

FC Facilitating Conditions

II Individual Innovativeness

PE Perceived Enjoyment

SE Self-efficacy

SN Social Norm

\section{References}

1. United Nations, D.f.S.D.G. Transforming our world: the 2030 Agenda for Sustainable Development 2015. 
2. Bank, W. Information and communications for development 2018: data-driven development 2018.

3. Mkude, C.G.; Wimmer, M.A. Using PESTELMO to Frame HCI Contextual Development in Developing Countries. International Conference on Social Implications of Computers in Developing Countries. Springer, 2019, pp. 326-333.

4. Li, Y.; Thomas, M.A. Adopting a Theory of Change Approach for ICT4D Project Impact Assessment-The Case of CMES Project. International Conference on Social Implications of Computers in Developing Countries. Springer, 2019, pp. 95-109.

5. Abdullah, F.; Ward, R. Developing a General Extended Technology Acceptance Model for E-Learning (GETAMEL) by analysing commonly used external factors. Computers in Human Behavior 2016, 56, 238-256.

6. Davis, F.D. A technology acceptance model for empirically testing new end-user information systems: Theory and results. PhD thesis, Massachusetts Institute of Technology, 1985.

7. Kim, Y.G.; Woo, E. Consumer acceptance of a quick response (QR) code for the food traceability system: Application of an extended technology acceptance model (TAM). Food Research International 2016, 85, 266-272.

8. Chuah, S.H.W.; Rauschnabel, P.A.; Krey, N.; Nguyen, B.; Ramayah, T.; Lade, S. Wearable technologies: The role of usefulness and visibility in smartwatch adoption. Computers in Human Behavior 2016, 65, 276-284.

9. Chen, K.; Chan, A.H.S. Gerontechnology acceptance by elderly Hong Kong Chinese: a senior technology acceptance model (STAM). Ergonomics 2014, 57, 635-652.

10. Chang, C.C.; Hung, S.W.; Cheng, M.J.; Wu, C.Y. Exploring the intention to continue using social networking sites: The case of Facebook. Technological Forecasting and Social Change 2015, 95, 48-56.

11. Koenig-Lewis, N.; Marquet, M.; Palmer, A.; Zhao, A.L. Enjoyment and social influence: predicting mobile payment adoption. The Service Industries Journal 2015, 35, 537-554.

12. Chen, C.f.; Xu, X.; Arpan, L. Between the technology acceptance model and sustainable energy technology acceptance model: Investigating smart meter acceptance in the United States. Energy research $\mathcal{E}$ social science 2017, 25, 93-104.

13. Muñoz-Leiva, F.; Climent-Climent, S.; Liébana-Cabanillas, F. Determinants of intention to use the mobile banking apps: An extension of the classic TAM model. Spanish Journal of Marketing-ESIC 2017, 21, 25-38.

14. Giovanis, A.N.; Binioris, S.; Polychronopoulos, G. An extension of TAM model with IDT and security/privacy risk in the adoption of internet banking services in Greece. EuroMed Journal of Business 2012.

15. Mercurio, D.I.; Hernandez, A.A. Understanding User Acceptance of Information System for Sweet Potato Variety and Disease Classification: An Empirical Examination with an Extended Technology Acceptance Model. 2020 16th IEEE International Colloquium on Signal Processing \& Its Applications (CSPA). IEEE, 2020, pp. 272-277.

16. Ajzen, I.; Fishbein, M.; Heilbroner, R.L. Understanding attitudes and predicting social behavior; Vol. 278, Prentice-hall Englewood Cliffs, NJ, 1980.

17. Ajzen, I. From intentions to actions: A theory of planned behavior. In Action control; Springer, 1985; pp. 11-39.

18. Davis, F.D. Perceived usefulness, perceived ease of use, and user acceptance of information technology. MIS quarterly 1989, pp. 319-340.

19. Tarhini, A.; Arachchilage, N.A.G.; Abbasi, M.S.; others. A critical review of theories and models of technology adoption and acceptance in information system research. International Journal of Technology Diffusion (IJTD) 2015, 6, 58-77.

20. Venkatesh, V.; Davis, F.D. A theoretical extension of the technology acceptance model: Four longitudinal field studies. Management science 2000, 46, 186-204.

21. Venkatesh, V.; Bala, H. Technology acceptance model 3 and a research agenda on interventions. Decision sciences 2008, 39, 273-315.

22. King, W.R.; He, J. A meta-analysis of the technology acceptance model. Information $\mathcal{E}$ management 2006, 43, 740-755.

23. Al-Emran, M.; Mezhuyev, V.; Kamaludin, A. Technology Acceptance Model in M-learning context: A systematic review. Computers \& Education 2018, 125, 389-412.

24. Davis, F.D.; Bagozzi, R.P.; Warshaw, P.R. User acceptance of computer technology: a comparison of two theoretical models. Management science 1989, 35, 982-1003. 
25. Akao, Y.; King, B. Quality function deployment: integrating customer requirements into product design; Vol. 21, Productivity press Cambridge, MA, 1990.

26. Bevilacqua, M.; Ciarapica, F.; Giacchetta, G. A fuzzy-QFD approach to supplier selection. Journal of Purchasing and Supply Management 2006, 12, 14-27.

27. Zhang, Z.; Chu, X. Risk prioritization in failure mode and effects analysis under uncertainty. Expert Systems with Applications 2011, 38, 206-214.

28. Ansari, A.; Modarress, B. Quality function deployment: the role of suppliers. International Journal of Purchasing and Materials Management 1994, 30, 27-35.

29. Luo, X.; Tang, J.; Wang, D. An optimization method for components selection using quality function deployment. The International Journal of Advanced Manufacturing Technology 2008, 39, 158-167.

30. Li, Y.L.; Tang, J.F.; Luo, X.G. An ECI-based methodology for determining the final importance ratings of customer requirements in MP product improvement. Expert Systems with Applications 2010, 37, 6240-6250.

31. Jeong, M.; Oh, H. Quality function deployment: An extended framework for service quality and customer satisfaction in the hospitality industry. International Journal of Hospitality Management 1998, 17, 375-390.

32. Cohen, L. Quality function deployment: how to make QFD work for you; Prentice Hall, 1995.

33. Bickness, B.; Bicknell, K.D. The road map to repeatable success: using QFD to implement change 1995.

34. Dolgun, L.E.; Köksal, G. Effective use of quality function deployment and Kansei engineering for product planning with sensory customer requirements: A plain yogurt case. Quality Engineering 2018, 30, 569-582.

35. Iranmanesh, S.H.; Thomson, V.; Salimi, M.H. Design parameter estimation using a modified QFD method to improve customer perception. Concurrent Engineering 2005, 13, 57-67.

36. Choi, I.K.; Kim, W.S.; Lee, D.; Kwon, D.S. A weighted qfd-based usability evaluation method for elderly in smart cars. International Journal of Human-Computer Interaction 2015, 31, 703-716.

37. Vezzetti, E.; Marcolin, F.; Guerra, A.L. QFD 3D: a new C-shaped matrix diagram quality approach. International Journal of Quality \& Reliability Management 2016.

38. Violante, M.G.; Marcolin, F.; Vezzetti, E.; Ulrich, L.; Billia, G.; Di Grazia, L. 3D Facial Expression Recognition for Defining Users' Inner Requirements-An Emotional Design Case Study. Applied Sciences 2019, 9, 2218.

39. Sun, S.; Ma, D.; Qian, H. Study on user experience of airport rail to air Transfer Mode based on QFD and service design methods. E3S Web of Conferences. E3S Web of Conferences, 2020, Vol. 179, p. 02030.

40. Salloum, S.A.; Alhamad, A.Q.M.; Al-Emran, M.; Monem, A.A.; Shaalan, K. Exploring students' acceptance of e-learning through the development of a comprehensive technology acceptance model. IEEE Access 2019, 7, 128445-128462.

41. Wingo, N.P.; Ivankova, N.V.; Moss, J.A. Faculty perceptions about teaching online: Exploring the literature using the technology acceptance model as an organizing framework. Online Learning 2017, 21, 15-35.

42. Scherer, R.; Siddiq, F.; Tondeur, J. The technology acceptance model (TAM): A meta-analytic structural equation modeling approach to explaining teachers' adoption of digital technology in education. Computers E Education 2019, 128, 13-35.

43. Sánchez-Prieto, J.C.; Olmos-Migueláñez, S.; García-Peñalvo, F.J. Informal tools in formal contexts: Development of a model to assess the acceptance of mobile technologies among teachers. Computers in Human Behavior 2016, 55, 519-528.

44. Tom Dieck, M.C.; Jung, T. A theoretical model of mobile augmented reality acceptance in urban heritage tourism. Current Issues in Tourism 2018, 21, 154-174.

45. Silva, A.G.; Canavari, M.; Sidali, K.L. A Technology Acceptance Model of common bean growers' intention to adopt Integrated Production in the Brazilian Central Region. Die Bodenkultur: Journal of Land Management, Food and Environment 2018, 68, 131-143.

46. Tubtiang, A.; Pipatpanuvittaya, S. A study of factors that affect attitude toward deploying smart-farm technologies in Tanud subdistrict, Damnoen Saduak district in Ratchaburi province. Journal of Food Science and Agricultural Technology (JFAT) 2015, 1, 144-148.

47. Far, S.T.; Rezaei-Moghaddam, K. Determinants of Iranian agricultural consultants' intentions toward precision agriculture: Integrating innovativeness to the technology acceptance model. Journal of the Saudi Society of Agricultural Sciences 2017, 16, 280-286.

48. Fountas, S.; Pedersen, S.M.; Blackmore, S. ICT in Precision Agriculture-diffusion of technology. ICT in agriculture: perspective of technological innovation, E. Gelb and A. Offer (eds), http://departments. agri. huji. ac. il/economics/gelb-main. html 2005. 
49. Okumua, O.F.; Faith, M.; others. Extending Technology Acceptance Model to Predict Innovation in Micro and Small Food Manufacturing Enterprises in Kenya. AJBUMA JOURNAL 2018, 4.

50. Rezaei, R.; Safa, L.; Ganjkhanloo, M.M. Understanding farmers' ecological conservation behavior regarding the use of integrated pest management-an application of the technology acceptance model. Global Ecology and Conservation 2020, 22, e00941.

51. Stenberg, J.A. A conceptual framework for integrated pest management. Trends in plant science 2017, 22, 759-769.

52. Nam, C.S.; Bahn, S.; Lee, R. Acceptance of assistive technology by special education teachers: A structural equation model approach. International Journal of Human-Computer Interaction 2013, 29, 365-377.

53. Cowan, D.; Turner-Smith, A.; others. The role of assistive technology in alternative models of care for older people, in [26. Research, HMSO. Citeseer, 1999.

54. Teo, T.; Lee, C.B.; Chai, C.S. Understanding pre-service teachers' computer attitudes: applying and extending the technology acceptance model. Journal of computer assisted learning 2008, 24, 128-143.

55. Teo, T. Examining the intention to use technology among pre-service teachers: An integration of the technology acceptance model and theory of planned behavior. Interactive Learning Environments 2012, 20, 3-18.

56. Wong, K.T.; others. Understanding Student Teachers' Behavioural Intention to Use Technology: Technology Acceptance Model (TAM) Validation and Testing. Online Submission 2013, 6, 89-104.

57. Sánchez-Prieto, J.C.; Olmos-Migueláñez, S.; J, G.P.F. MLearning and pre-service teachers: An assessment of the behavioral intention using an expanded TAM model. Computers in Human Behavior 2017, 72, 644-654.

58. Islam, M.S.; Grönlund, A. Factors influencing the adoption of mobile phones among the farmers in Bangladesh: Theories and practices. ICTer 2011, 4.

59. Zhou, D.; others. The acceptance of solar water pump technology among rural farmers of northern Pakistan: A structural equation model. Cogent Food \& Agriculture 2017, 3, 1280882.

60. Manis, K.T.; Choi, D. The virtual reality hardware acceptance model (VR-HAM): Extending and individuating the technology acceptance model (TAM) for virtual reality hardware. Journal of Business Research 2019, 100, 503-513.

61. Lee, J.; Kim, J.; Choi, J.Y. The adoption of virtual reality devices: The technology acceptance model integrating enjoyment, social interaction, and strength of the social ties. Telematics and Informatics 2019, $39,37-48$.

62. Kucukusta, D.; Law, R.; Besbes, A.; Legohérel, P. Re-examining perceived usefulness and ease of use in online booking. International Journal of Contemporary Hospitality Management 2015.

63. Dumpit, D.Z.; Fernandez, C.J. Analysis of the use of social media in Higher Education Institutions (HEIs) using the Technology Acceptance Model. International Journal of Educational Technology in Higher Education 2017, $14,5$.

64. Alharbi, S.; Drew, S. Using the technology acceptance model in understanding academics' behavioural intention to use learning management systems. International Journal of Advanced Computer Science and Applications 2014, 5, 143-155.

65. Shin, W.S.; Kang, M. The use of a mobile learning management system at an online university and its effect on learning satisfaction and achievement. International Review of Research in Open and Distributed Learning 2015, 16, 110-130.

66. Calisir, F.; Altin Gumussoy, C.; Bayraktaroglu, A.E.; Karaali, D. Predicting the intention to use a web-based learning system: Perceived content quality, anxiety, perceived system quality, image, and the technology acceptance model. Human Factors and Ergonomics in Manufacturing $\mathcal{E}$ Service Industries 2014, 24, 515-531.

67. Mohammadi, H. Investigating users' perspectives on e-learning: An integration of TAM and IS success model. Computers in human behavior 2015, 45, 359-374.

68. Al-Rahmi, W.M.; Yahaya, N.; Aldraiweesh, A.A.; Alamri, M.M.; Aljarboa, N.A.; Alturki, U.; Aljeraiwi, A.A. Integrating technology acceptance model with innovation diffusion theory: An empirical investigation on students' intention to use E-learning systems. IEEE Access 2019, 7, 26797-26809.

69. Binyamin, S.S.; Rutter, M.; Smith, S. Extending the technology acceptance model to understand students use of learning management systems in Saudi higher education. International Journal of Emerging Technologies in Learning (iJET) 2019, 14, 4-21. 
70. Al-Adwan, A.; Al-Adwan, A.; Smedley, J. Exploring students acceptance of e-learning using Technology Acceptance Model in Jordanian universities. International Journal of Education and Development using ICT 2013, 9 .

71. Fathema, N.; Shannon, D.; Ross, M. Expanding the Technology Acceptance Model (TAM) to examine faculty use of Learning Management Systems (LMSs) in higher education institutions. Journal of Online Learning E Teaching 2015, 11.

72. Chang, C.T.; Hajiyev, J.; Su, C.R. Examining the students' behavioral intention to use e-learning in Azerbaijan? The general extended technology acceptance model for e-learning approach. Computers $\mathcal{E}$ Education 2017, 111, 128-143.

73. Al-Gahtani, S.S. Empirical investigation of e-learning acceptance and assimilation: A structural equation model. Applied Computing and Informatics 2016, 12, 27-50.

74. Lee, Y.H.; Hsieh, Y.C.; Chen, Y.H. An investigation of employees' use of e-learning systems: applying the technology acceptance model. Behaviour \& Information Technology 2013, 32, 173-189.

75. Yeou, M. An investigation of students' acceptance of Moodle in a blended learning setting using technology acceptance model. Journal of Educational Technology Systems 2016, 44, 300-318.

76. Estriegana, R.; Medina-Merodio, J.A.; Barchino, R. Student acceptance of virtual laboratory and practical work: An extension of the technology acceptance model. Computers $\mathcal{E}$ Education 2019, 135, 1-14.

77. Shyu, S.H.P.; Huang, J.H. Elucidating usage of e-government learning: A perspective of the extended technology acceptance model. Government Information Quarterly 2011, 28, 491-502.

78. Wu, B.; Chen, X. Continuance intention to use MOOCs: Integrating the technology acceptance model (TAM) and task technology fit (TTF) model. Computers in Human Behavior 2017, 67, 221-232.

79. Revythi, A.; Tselios, N. Extension of Technology Acceptance Model by using System Usability Scale to assess behavioral intention to use e-learning. Education and Information technologies 2019, 24, 2341-2355.

80. Khor, E.T. An analysis of ODL student perception and adoption behavior using the technology acceptance model. International Review of Research in Open and Distributed Learning 2014, 15, 275-288.

81. Liu, X. Empirical testing of a theoretical extension of the technology acceptance model: An exploratory study of educational wikis. Communication Education 2010, 59, 52-69.

82. Tarhini, A.; Hassouna, M.; Abbasi, M.S.; Orozco, J. Towards the Acceptance of RSS to Support Learning: An empirical study to validate the Technology Acceptance Model in Lebanon. Electronic Journal of e-Learning 2015, 13, 30-41.

83. Cheung, R.; Vogel, D. Predicting user acceptance of collaborative technologies: An extension of the technology acceptance model for e-learning. Computers $\mathcal{E}$ education 2013, 63, 160-175.

84. Lee, D.Y.; Lehto, M.R. User acceptance of YouTube for procedural learning: An extension of the Technology Acceptance Model. Computers \& Education 2013, 61, 193-208.

85. Vidanapathirana, N.; Hirimburegama, K.; Hirimburegama, W.; Nelka, S. Exploring farmers acceptance of e-learning using Technology Acceptance Model-case study in Sri Lanka. Proceedings of EDULEARN15 Conference 6th-8th July 2015, Barcelona, Spain 2015.

86. Verma, P.; Sinha, N. Technology acceptance model revisited for mobile based agricultural extension services in India. Management Research E Practice 2016, 8.

87. Verma, P.; Sinha, N. Integrating perceived economic wellbeing to technology acceptance model: The case of mobile based agricultural extension service. Technological forecasting and social change 2018, 126, 207-216.

88. Amin, M.K.; Li, J.; others. Applying Farmer Technology Acceptance Model to Understand Farmer's Behavior Intention to use ICT Based Microfinance Platform: A Comparative analysis between Bangladesh and China. WHICEB, 2014, p. 31.

89. Das V, J.; Sharma, S.; Kaushik, A. Views of Irish farmers on smart farming technologies: An observational study. AgriEngineering 2019, 1, 164-187.

90. Huang, T.L.; Liao, S. A model of acceptance of augmented-reality interactive technology: the moderating role of cognitive innovativeness. Electronic Commerce Research 2015, 15, $269-295$.

91. Huang, H.M.; Liaw, S.S.; Lai, C.M. Exploring learner acceptance of the use of virtual reality in medical education: a case study of desktop and projection-based display systems. Interactive Learning Environments 2016, 24, 3-19. 
92. Naspetti, S.; Mandolesi, S.; Buysse, J.; Latvala, T.; Nicholas, P.; Padel, S.; Van Loo, E.J.; Zanoli, R. Determinants of the acceptance of sustainable production strategies among dairy farmers: Development and testing of a modified technology acceptance model. Sustainability 2017, 9, 1805.

93. Caffaro, F.; Cremasco, M.M.; Roccato, M.; Cavallo, E. Drivers of farmers' intention to adopt technological innovations in Italy: The role of information sources, perceived usefulness, and perceived ease of use. Journal of Rural Studies 2020.

94. Schoonenboom, J. Using an adapted, task-level technology acceptance model to explain why instructors in higher education intend to use some learning management system tools more than others. Computers $\mathcal{E}$ Education 2014, 71, 247-256.

95. Sharifzadeh, M.S.; Damalas, C.A.; Abdollahzadeh, G.; Ahmadi-Gorgi, H. Predicting adoption of biological control among Iranian rice farmers: An application of the extended technology acceptance model (TAM2). Crop Protection 2017, 96, 88-96.

96. Bahtera, N.I.; Atmaja, E.J.J.; Setiawan, I.; Irwanto, R. THE TECHNOLOGY ACCEPTANCE MODEL (TAM) ON PEPPER FARMERS IN BANGKA, INDONESIA. Journal of Information 2019, 4, 48-58.

97. Punnoose, A.C. Determinants of intention to use eLearning based on the technology acceptance model. Journal of Information Technology Education: Research 2012, 11, 301-337.

98. Ibrahim, R.; Leng, N.; Yusoff, R.; Samy, G.; Masrom, S.; Rizman, Z. E-learning acceptance based on technology acceptance model (TAM). Journal of Fundamental and Applied Sciences 2017, 9, 871-889.

99. Park, S.Y.; Nam, M.W.; Cha, S.B. University students' behavioral intention to use mobile learning: Evaluating the technology acceptance model. British journal of educational technology 2012, 43, 592-605.

100. Nikou, S.A.; Economides, A.A. Mobile-Based Assessment: Integrating acceptance and motivational factors into a combined model of Self-Determination Theory and Technology Acceptance. Computers in Human Behavior 2017, 68, 83-95.

101. Ahmad, T.B.T.; Madarsha, K.B.; Zainuddin, A.M.H.; Ismail, N.A.H.; Nordin, M.S. Faculty's acceptance of computer based technology: Cross-validation of an extended model. Australasian journal of educational technology 2010, 26.

102. Wong, K.T.; Teo, T.; Russo, S. Influence of gender and computer teaching efficacy on computer acceptance among Malaysian student teachers: An extended technology acceptance model. Australasian Journal of Educational Technology 2012, 28.

103. Padilla-Meléndez, A.; Del Aguila-Obra, A.R.; Garrido-Moreno, A. Perceived playfulness, gender differences and technology acceptance model in a blended learning scenario. Computers $\mathcal{E}$ Education 2013, 63, 306-317.

104. Tarhini, A.; Hone, K.; Liu, X. Measuring the moderating effect of gender and age on e-learning acceptance in England: A structural equation modeling approach for an extended technology acceptance model. Journal of Educational Computing Research 2014, 51, 163-184.

105. Al-Azawei, A.; Lundqvist, K. Learner Differences in Perceived Satisfaction of an Online Learning: An Extension to the Technology Acceptance Model in an Arabic Sample. Electronic Journal of e-Learning 2015, 13, 408-426.

106. Felder, R.M.; Silverman, L.K.; others. Learning and teaching styles in engineering education. Engineering education 1988, 78, 674-681.

107. Al-Azawei, A.; Parslow, P.; Lundqvist, K. Investigating the effect of learning styles in a blended e-learning system: An extension of the technology acceptance model (TAM). Australasian Journal of Educational Technology 2017, 33.

108. Tarhini, A.; Hone, K.; Liu, X.; Tarhini, T. Examining the moderating effect of individual-level cultural values on users' acceptance of E-learning in developing countries: a structural equation modeling of an extended technology acceptance model. Interactive Learning Environments 2017, 25, 306-328.

109. Venkatesh, V. Determinants of perceived ease of use: Integrating perceived behavioral control, computer anxiety and enjoyment into the technology acceptance model. Information systems research 2000, 11, 342-365.

110. Lee, B.C.; Yoon, J.O.; Lee, I. Learners' acceptance of e-learning in South Korea: Theories and results. Computers \& Education 2009, 53, 1320-1329.

111. Lee, Y.C. An empirical investigation into factors influencing the adoption of an e-learning system. Online information review 2006. 
112. Thompson, R.; Compeau, D.; Higgins, C. Intentions to use information technologies: An integrative model. Journal of Organizational and End User Computing (JOEUC) 2006, 18, 25-46.

113. Fazio, R.H.; Zanna, M.P. Direct experience and attitude-behavior consistency. In Advances in experimental social psychology; Elsevier, 1981; Vol. 14, pp. 161-202.

114. Karahanna, E.; Straub, D.W.; Chervany, N.L. Information technology adoption across time: a cross-sectional comparison of pre-adoption and post-adoption beliefs. MIS quarterly 1999, pp. 183-213.

115. Venkatesh, V.; Morris, M.G.; Davis, G.B.; Davis, F.D. User acceptance of information technology: Toward a unified view. MIS quarterly 2003, pp. 425-478.

116. Agarwal, R.; Prasad, J. A conceptual and operational definition of personal innovativeness in the domain of information technology. Information systems research 1998, 9, 204-215.

117. Liu, Y.; Li, H.; Carlsson, C. Factors driving the adoption of m-learning: An empirical study. Computers $\mathcal{E}$ Education 2010, 55, 1211-1219.

118. Park, Y.; Son, H.; Kim, C. Investigating the determinants of construction professionals' acceptance of web-based training: An extension of the technology acceptance model. Automation in construction 2012, 22, 377-386.

119. Compeau, D.R.; Higgins, C.A. Application of social cognitive theory to training for computer skills. Information systems research 1995, 6, 118-143.

120. Compeau, D.R.; Higgins, C.A. Computer self-efficacy: Development of a measure and initial test. MIS quarterly 1995, pp. 189-211.

121. Elliott, K.M.; Hall, M.C.; Meng, J.G. Consumers' intention to use self-scanning technology: the role of technology readiness and perceptions toward self-service technology. Academy of Marketing Studies Journal 2013, 17, 129.

122. Delone, W.H.; McLean, E.R. The DeLone and McLean model of information systems success: a ten-year update. Journal of management information systems 2003, 19, 9-30.

123. Fishbein, M.; Ajzen, I. Belief, attitude, intention, and behavior: An introduction to theory and research 1977.

124. Ajzen, I.; others. The theory of planned behavior. Organizational behavior and human decision processes 1991, 50, 179-211.

125. Lleras, C. Path analysis. Encyclopedia of social measurement 2005, 3, 25-30.

126. Cohen, J. A power primer. Psychological bulletin 1992, 112, 155.

127. Sagnier, C.; Loup-Escande, E.; Lourdeaux, D.; Thouvenin, I.; Valléry, G. User acceptance of virtual reality: an extended technology acceptance model. International Journal of Human-Computer Interaction 2020, 36, 993-1007.

128. Li, Y.; Qi, J.; Shu, H. Review of relationships among variables in TAM. Tsinghua Science E Technology 2008, 13, 273-278.

129. Van Raaij, E.M.; Schepers, J.J. The acceptance and use of a virtual learning environment in China. Computers $\mathcal{E}$ Education 2008, 50, 838-852.

130. Almaiah, M.A.; Jalil, M.A.; Man, M. Extending the TAM to examine the effects of quality features on mobile learning acceptance. Journal of Computers in Education 2016, 3, 453-485.

131. Chen, K.; Chen, J.V.; Yen, D.C. Dimensions of self-efficacy in the study of smart phone acceptance. Computer Standards E Interfaces 2011, 33, 422-431.

132. Wang, Y.S.; Wu, M.C.; Wang, H.Y. Investigating the determinants and age and gender differences in the acceptance of mobile learning. British journal of educational technology 2009, 40, 92-118.

133. Purnomo, S.H.; Lee, Y.H. E-learning adoption in the banking workplace in Indonesia: an empirical study. Information Development 2013, 29, 138-153.

134. Cheng, S.I.; Chen, S.C.; Yen, D.C. Continuance intention of E-portfolio system: A confirmatory and multigroup invariance analysis of technology acceptance model. Computer Standards $\mathcal{E}$ Interfaces 2015, 42, 17-23.

135. Jeong, N.; Yoo, Y.; Heo, T.Y. Moderating effect of personal innovativeness on mobile-RFID services: Based on Warshaw's purchase intention model. Technological Forecasting and Social Change 2009, 76, 154-164.

136. Ryan, R.M.; Deci, E.L. Intrinsic and extrinsic motivations: Classic definitions and new directions. Contemporary educational psychology 2000, 25, 54-67. 
137. Venkatesh, V.; Davis, F.D. A model of the antecedents of perceived ease of use: Development and test. Decision sciences 1996, 27, 451-481.

138. Chang, S.C.; Tung, F.C. An empirical investigation of students' behavioural intentions to use the online learning course websites. British Journal of Educational Technology 2008, 39, 71-83.

139. Lee, J.K.; Lee, W.K. The relationship of e-Learner's self-regulatory efficacy and perception of e-Learning environmental quality. Computers in human Behavior 2008, 24, 32-47. 